\title{
Analysis of Survey of Interdisciplinary Unification of Biomedical Laboratory Science
}

\author{
Hong Sung Kim ${ }^{1}$, Ji-Hyuk Kang ${ }^{2}$, Man-Gil Yang ${ }^{3}$, Chang-Eun Park ${ }^{4}$, Kyung-A Shin ${ }^{5}$, Pil Seung Kwon ${ }^{6}$ \\ ${ }^{1}$ Department of Biomedical Laboratory Science, Korea Nazarene University, Cheonan, Korea \\ ${ }^{2}$ Department of Biomedical Laboratory Science, DaeJeon University, Daejeon, Korea \\ ${ }^{3}$ Department of Biomedical Laboratory Science, Sanji University, Wonju, Korea \\ ${ }^{4}$ Department of Biomedical Laboratory Science, Namseoul University, Cheonan, Korea \\ ${ }^{5}$ Department of Clinical Laboratory Science, Shinsung University, Dangjin, Korea \\ ${ }^{6}$ Department of Clinical Laboratory Science, Wonkwang Health Science University, lksan, Korea
}

\section{임상병리학과 학제단일화에 대한 설문조사 분석}

\author{
김홍성, 강지혁 ${ }^{2}$, 양만길, 박창은, 신경아, 권필승 6 \\ ${ }^{1}$ 나사렛대학교 임상병리학과, ${ }^{2}$ 대전대학교 임상병리학과, ${ }^{3}$ 상지대학교 임상병리학과, ${ }^{4}$ 남서울대학교 임상병리학과, ${ }^{5}$ 신성대학교 임상병리학과, \\ ${ }^{6}$ 원광보건대학교 임상병리학과
}

\begin{abstract}
Opinions regarding interdisciplinary unification of medical laboratory science were analyzed by an online questionnaire distributed to 255 professors and 4,000 hospital practitioners in January of 2018. The recovery rate was $79(30.9 \%)$ for professors and 1,368 (34.2\%) for hospital practitioners. In the perception survey on the duality of interdisciplinary, both the professors and the hospital practitioners reported that they felt interdisciplinary integration is necessary. The prerequisite of four-year integration was the establishment of institute of accreditation and standardization of curriculum, and the requirements for the four-year integration were considered important for adjustment of student quota and standardization of curriculum. In the four-year integrated approach, the opinion that only universities that passed the accreditation evaluation should operate a four-year system was highest among professors and hospital practitioners. The optimum capacity of university students was less than 40 in cases of 4-year integration. In conclusion, the above results suggest that the professors and hospital practitioners realize 4-year interdisciplinary integration is necessary to produce a competent medical technologist, and the institute of accreditation, standardization of curriculum, and student quota adjustment should be presupposed for 4-year integration.
\end{abstract}

Key words: Institution of accreditation, Interdisciplinary reorganization, Interdisciplinary unification of four-year courses, Standardization of curriculum, Student quota adjustment

\footnotetext{
This is an Open Access article distributed under the terms of the Creative Commons Attribution Non-Commercial License (http://creativecommons.org/licenses/by-nc/4.0) which permits unrestricted non-commercial use, distribution, and reproduction in any medium, provided the original work is properly cited.

Copyright (C) 2018 The Korean Society for Clinical Laboratory Science. All rights reserved.
}

\author{
Corresponding author: Pil Seung Kwon \\ Department of Clinical Laboratory Science, \\ Wonkwang Health Science University, \\ 514 lksan-daero, Iksan 54538, Korea \\ Tel: 82-63-840-1210 \\ Fax: 82-63-840-1219 \\ E-mail:pskwon@wu.ac.kr
}

Received: July 30, 2018 Revised ${ }^{\text {st: }}$ : August 20, 2018 Revised 2 ${ }^{\text {nd }}$ : August 22, 2018 Accepted: August 27, 2018

\section{서 론}

우리나라 임상병리사 양성교육은 1963년 임상병리과가 처 음 개설되고 1979 년 교육부의 학제 개편에 따라 모든 임상병리 과가 2년제 전문대학으로 개편되어 교육되어 왔다. 이후 1987
년 4년 학위과정의 임상병리학과를 개설하였으며 1991년 모든 2 년제 전문대학의 학제가 3 년제로 연장되면서 학제가 이원화 되었다. 현재 임상병리(학)과는 전국에 53개 대학교에 개설되 어 있으며 이중 4년제 대학교가 27개, 3년제 대학교가 26개로 분포되어 있다. 3 년제 대학 중 10 개 대학은 전공심화 - 학점은 
행제 $(3+1$ 과정)를 운영하고 있다[1]. 이와 같이 우리나라 임상 병리사 양성을 위한 교육제도는 이원화되어 있지만, 졸업 후 동 일한 면허를 취득하고 사회에서의 업무가 명확한 구분이 되어 있지 않는 것이 현실이다. 또한 이런 이원화는 학습한 교육내용 의 차이, 절대 이수학점의 차이가 발생하며 3, 4년제 학사운영 방법의 차이점이 산업현장에서 요구하는 직무와 불일치하고 미 래지향적인 4차 산업혁명시대의 대비가 어려운 것이 현실이다 [2-4].

3,4 년제 대학의 교육과정 운영은 상당한 차이를 보이고 있 다. 4 년제 학사과정에서의 교과과정 운영은 부전공 선택에 따른 자율성이 부여되어 있어서 임상현장에서 반드시 필요한 전공 지식임에도 불구하고 이수하지 않는 경우가 흔하게 발생하며 여기에 수반되는 임상현장의 불만의 목소리도 간과하기 어려운 현실이다. 반면에 3 년제 전문학사과정의 경우는 개설된 모든 대 학의 교육과정이 유사하며 학생들에게 과목 이수 자율권이 부 여 되어있지 않기 때문에 동일성이 유지되고 있는 점에서 학사 과정 운영과차이가 있다 할 수 있겠다. 이러한 운영상의 상이함 은 상대적으로 취업현장에서 역 차별로 나타나고 있음을 부인 할 수 없다. 학사과정과 전문학사과정 간의 1 년 교육시간 차이 는 자율성과 여유 그리고 입학 자원의 질적 차이로 나타난다[5]. 이러한 현상을 해소하는 방법의 최선은 학제 단일화를 통해 임 상 현장에서 필요한 최소한 이수과목에 대한 공통성을 부여하 고 임상현장 적응력 향상을 위한 실습 의무과정 등을 충분히 부 여하는 것이다. 이미 4년제 단일화를 시행하고 있는 간호학과를 비롯해 많은 보건관련 학과들이 4년제 통합의 필요성을 제기하 고 있다[6, 7]. 또한 4년제 과정 교육이 무한대로 넓어지고 있는 생명과학 기반인 의학의 영역에 적응하기 위해 새로운 교육내 용을 수용하여 국민건강에 이바지하고 의료의 질을 향상하는 계기를 마련하는 것에 필요하다는 것이 여러 연구를 통해서 제 시되고 있다[8, 9].

본 연구에서는 보건의료 환경변화에 따른 임상병리사 양성 을 위해 교수들과 병원실무자를 대상으로 설문조사를 시행하여 우리나라 임상병리학 학제에 대한 만족도, 각 학제별 임상병리 사 양성에 대한 적합성, 그리고 만약 4년제로 통합한다면 통합 전제조건, 통합방식, 필수조건, 대학정원 적정인원에 대한 의식 을 조사하고 분석하여 필요한 정책방향을 제시하고 가장 효과 적인 임상병리사 인력 양성을 위한 학제의 기틀을 마련하는 기 초자료를 제공하는데 있다.

\section{재료 및 방법}

\section{1. 연구 설계}

문헌조사 분석과 타당성 검토를 통해 작성한 설문을 이용하 여 국내 임상병리사의 인력양성을 위한 학제 단일화에 대한 교 수와 병원실무자들의 의견과 개선방안을 도출한다.

\section{2. 대상과 조사방법}

문헌조사자료와 더불어 대학과 임상실무자들로부터 타당성 에 관한 조언과 자문을 얻어서 설문조사 내용을 확보하였고, 설 문조사는 이메일과 웹문서를 통해 시행하였다. 설문내용은 전 국 임상병리학과 교수와 병원 실무자들에게 2018년 1월 18일 부터 25일까지 배포하고 수집되었다. 설문 요청한 대학교수 255 명중 79명(30.9\%)이 응답하였고, 병원실무자 4,000명 중 1,368 명(34.2\%)이 응답하였다. 본 연구목적을 고려하여 설문 내용은 일반사항 문항, 학제단일화 적합성, 문제점, 개선점 문항 으로 구성하였다. 문항은 전혀 그렇지 않다(1점)부터 매우 그렇 다(5점)까지 5점 리커트 척도 문항과 선택형 문항으로 구성하였 다.

\section{3. 통계분석}

수집된 자료들은 SPSS 18.0 (SPSS Inc., Chicago, IL, USA) 으로 분석되었다. 수집된 자료의 타당성은 백분율, 평균값, 표준 편차를 통해 제시하였다. 두 집단간의 결과의 유의성은 student t-test에 의해 제시하였다. 모든 통계량의 유의수준은 $P<0.05$ 로 판정하였다.

\section{결 과}

\section{1. 일반적 특성}

설문에 참가한 교수집단의 성별은 남자가 $73.4 \%$ 로 많았고, 연령은 40 대가 $38 \%$ 로 가장 많았으며, 최종학력은 박사 $92.4 \%$ 로 가장 많았다. 면허취득년도는 10 년 이하 $6.4 \%, 11$ 년 이상 $79.8 \%$ 를 보였고, 근무지역은 충청남도가 가장 많은 $13.9 \%$ 로 분포되었다. 병원 실무자 응답자의 성별은 여자가 $74.8 \%$ 로 많 았고, 연령은 20 대가 $32.7 \%$ 로 가장 많았으며, 연령은 20 30 대 연령층이 $64.1 \%$ 로 나타났다. 학력은 전문학사가 $43.8 \%$ 로 가장 많았으며, 면허취득년도는 10 년 이하 $52.9 \%, 11$ 년 이상 $46.7 \%$ 를 보였고, 근무지역은 서울이 가장 많은 $20.6 \%$ 로 분포 되었다. 서울, 경기, 광역시에 $70 \%$ 이상이 근무하고 있음을 확인 하였다(Table 1). 
Table 1. The general information of professors and medical technologists

\begin{tabular}{|c|c|c|c|}
\hline \multicolumn{2}{|c|}{ Classification } & Percentage (\%) & Note \\
\hline \multicolumn{4}{|c|}{ Professors $(\mathrm{N}=79)$} \\
\hline \multirow[t]{2}{*}{ Sex } & Male & 73.4 & Male $>$ Female \\
\hline & Female & 26.6 & \\
\hline \multirow[t]{5}{*}{ Age } & Twenties & 1.3 & Fourties $>$ Sixties $>$ Fifteis $>$ Thirties \\
\hline & Thirties & 6.3 & \\
\hline & Fourties & 38.0 & \\
\hline & Fifties & 26.6 & \\
\hline & Sixties & 27.8 & \\
\hline \multirow{5}{*}{$\begin{array}{l}\text { Academic } \\
\text { degree }\end{array}$} & Associate & 3.8 & Doctor $>$ Master \\
\hline & Bachelor & 0.0 & \\
\hline & Bachelor after associate & 0.0 & \\
\hline & Master & 3.8 & \\
\hline & Doctor & 92.4 & \\
\hline \multirow{7}{*}{$\begin{array}{l}\text { Native school } \\
\text { region }\end{array}$} & Seoul & 24.1 & Seoul $>$ Gyeongsang $>$ Chungcheong $>$ Jeolla $>$ \\
\hline & Gyeonggi & 11.4 & Gyeonggi=Gangwon, Jeju \\
\hline & Chungcheong & 17.7 & \\
\hline & Gyeongsang & 21.5 & \\
\hline & Jeolla & 12.7 & \\
\hline & Gangwon, Jeju & 11.4 & \\
\hline & Other & 1.3 & \\
\hline \multirow{6}{*}{$\begin{array}{l}\text { License } \\
\text { acquisition year }\end{array}$} & $1 \sim 5$ year & 1.3 & Below 10 year: 6.4\%, above 11 year: $79.8 \%$ \\
\hline & $6 \sim 10$ year & 5.1 & \\
\hline & $11 \sim 15$ year & 3.8 & \\
\hline & 16 20 year & 3.8 & \\
\hline & Above 20 year & 72.2 & \\
\hline & Other & 13.9 & \\
\hline \multirow[t]{3}{*}{ Interdisplinary } & 3-year & 30.4 & 4-year $>3+1$ year $>3$-year \\
\hline & $3+1-$ year & 34.2 & \\
\hline & 4-year & 35.4 & \\
\hline \multirow[t]{17}{*}{ Working region } & Seoul & 1.3 & Chungnam $>$ Gyeonggi $>$ Jeonnam $>$ Daejeon=Gyeongnam $>$ \\
\hline & Busan & 5.1 & Daegu $>$ Gyeongbuk=Jeonbuk $>$ Busan=Chungbuk \\
\hline & Daegu & 7.6 & \\
\hline & Incheon & 0.0 & \\
\hline & Gwangju & 2.5 & \\
\hline & Daejeon & 10.1 & \\
\hline & Ulsan & 0.0 & \\
\hline & Gyeonggi & 12.7 & \\
\hline & Chungbuk & 5.1 & \\
\hline & Chungnam & 13.9 & \\
\hline & Jeonbuk & 6.3 & \\
\hline & Jeonnam & 11.4 & \\
\hline & Gyeongbuk & 6.3 & \\
\hline & Gyeongnam & 10.1 & \\
\hline & Gangwon & 3.8 & \\
\hline & Jeju & 3.8 & \\
\hline & Other & 0.0 & \\
\hline \multicolumn{4}{|c|}{ Medical technologists $(\mathrm{N}=1,368)$} \\
\hline \multirow[t]{2}{*}{ Sex } & Male & 25.20 & Female $>$ male \\
\hline & Female & 74.80 & \\
\hline \multirow[t]{5}{*}{ Age } & Twenties & 32.70 & Twenties $>$ Thirties $>$ Fourties $>$ Fifties \\
\hline & Thirties & 31.40 & \\
\hline & Fourties & 23.50 & \\
\hline & Fifties & 11.40 & \\
\hline & Sixties & 1.00 & \\
\hline
\end{tabular}


Table 1. Continued

\begin{tabular}{|c|c|c|c|}
\hline \multicolumn{2}{|c|}{ Classification } & \multirow{3}{*}{$\begin{array}{c}\text { Percentage (\%) } \\
43.80 \\
23.40\end{array}$} & \multirow{3}{*}{$\begin{array}{c}\text { Note } \\
\text { Associate }>\text { Bachelor }>\text { Bachelor after associate }> \\
\text { Master }>\text { Doctor }\end{array}$} \\
\hline Academic & Associate & & \\
\hline degree & Bachelor & & \\
\hline & Bachelor after associate & 23.00 & \\
\hline & Master & 8.00 & \\
\hline & Doctor & 1.80 & \\
\hline \multirow{7}{*}{$\begin{array}{l}\text { Native school } \\
\text { region }\end{array}$} & Seoul & 4.30 & Gyeongsang $>$ Gyeonggi $>$ Jeolla $>$ Chngcheong \\
\hline & Gyeonggi & 18.30 & \\
\hline & Chungcheong & 14.80 & \\
\hline & Gyeongsang & 35.20 & \\
\hline & Jeolla & 17.60 & \\
\hline & Gangwon, Jeju & 3.70 & \\
\hline & Other & 5.60 & \\
\hline \multirow{6}{*}{$\begin{array}{l}\text { License } \\
\text { acquisition year }\end{array}$} & $1 \sim 5$ year & 32.20 & Below 10 year: 52.9\%, above 11 year: 46.7\% \\
\hline & $6 \sim 10$ year & 20.70 & \\
\hline & $11 \sim 15$ year & 12.60 & \\
\hline & 16 20 year & 12.80 & \\
\hline & Above 20 year & 21.30 & \\
\hline & Other & 0.40 & \\
\hline \multirow[t]{5}{*}{ Acquisition degree } & 2, 3-year degree & 51.00 & 2,3 year degree $>4$-year degree $>3+1$-year degree $>$ \\
\hline & $3+1$ year degree & 10.90 & master, doctor \\
\hline & 4-year degree & 19.00 & \\
\hline & Master, doctor & 7.00 & \\
\hline & Other & 12.10 & \\
\hline \multirow[t]{17}{*}{ Working region } & Seoul & 20.60 & Seoul $>$ Busan > Gyeonggi > Incheon > Gyeongnam > \\
\hline & Busan & 15.60 & Daegu $>$ Gyeongbuk=Gwangju $>$ Daejeon \\
\hline & Daegu & 4.40 & \\
\hline & Incheon & 6.40 & \\
\hline & Gwangju & 4.00 & \\
\hline & Daejeon & 3.90 & \\
\hline & Ulsan & 2.70 & \\
\hline & Gyeonggi & 13.80 & \\
\hline & Chungbuk & 3.60 & \\
\hline & Chungnam & 3.50 & \\
\hline & Jeonbuk & 3.70 & \\
\hline & Jeonnam & 2.90 & \\
\hline & Gyeongbuk & 4.00 & \\
\hline & Gyeongnam & 6.30 & \\
\hline & Gangwon & 2.30 & \\
\hline & Jeju & 1.00 & \\
\hline & Other & 1.20 & \\
\hline
\end{tabular}

\section{2. 학제에 대한 의견과 문제점}

설문에 참여한 교수 중 3 년제 대학에 종사자는 $64.6 \%, 4$ 년제 종사자는 $35.4 \%$ 였다. 교수들과 병원실무자들에서 현행 3 년제 와 4년제의 이원화된 학제의 유지에 대한 의견은 각각 $6.3 \%$, $12 \%, 3$ 년제로 통합되어야 한다는 의견은 각각 $3.8 \%, 6 \%$ 인 반 면 4년제로 통합되어야 한다는 의견이 각각 $89.9 \%, 76 \%$ 로 높게 나타났다(Figure 1).

현재 임상병리학과 학제가 임상병리사 양성에 적합한지에 대한 의견에서 3 년제 학제의 경우 교수들과 병원실무자들은 각 각 $64.2 \%, 43.1 \%$ 로 적합하지 않다고 응답하였고, $3+1$ 과정(전

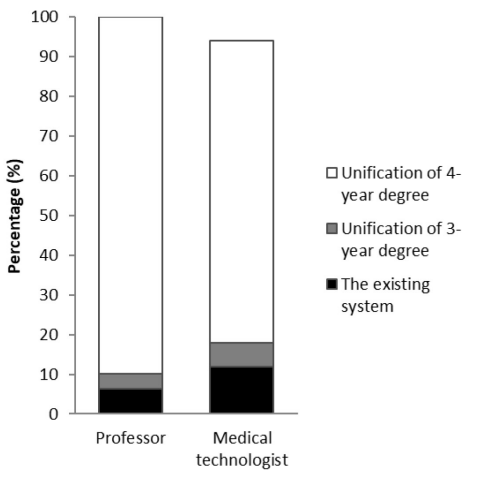

Figure 1. Analysis of the survey response on the propriety of present interdisciplinary of medical laboratory science between professors and medical technologists. 
공심화, 학점은행제)의 경우에도 각각 $64.6 \%, 43.4 \%$ 로 적합하 지 않다고 응답하였다. 반면, 4 년제 학제의 경우 교수들과 병원 실무자들은 적합하다는 의견이 각각 $84.8 \%, 57 \%$ 로 높게 나타 났다(Table 2). 각 학제별로 적합하지 않다고 생각하는 이유에 대한 조사에서 3 년제 학제의 경우, 교수들은 수업 년 한이 짧은 관계로 인한 심화교육과 기술습득의 어려움이 $30.4 \%$, 동등한 학위인정의 어려움이 $22.8 \%$ 로 조사되었고, 병원실무자들은 동 등한 학위인정의 어려움이 $33 \%$, 심화교육과 기술습득의 어려 움이 $18.7 \%$ 로 확인되었다(Figure 2A). $3+1$ 과정(전공심화, 학 점은행제)의 경우, 교수들과 병원실무자들은 단순 학위취득 수 단으로 경제적 손실만 가중되는 점이 각각 $36.7 \%, 30.9 \%$ 로 나 타났고, 4 년제 학제와 동등한 대우를 받기 어렵다는 점이 각각 $34.2 \%, 28 \%$ 로 나타났다(Figure 2B). 4년제 학제의 경우, 대부 분이 적합하다는 의견을 보여주었으나, 적합하지 않다고 생각 하는 이유에서는 교수들과 병원실무자 모두 3년제와 동일한 면 허증 취득을 위해 1 년의 추가시간이 필요하지 않다는 의견이 각
각 $13.5 \%, 7.6 \%$ 로 나타났다(Figure 2C). Figure 2에서 응답 없 음 항목은 적합하다고 생각하는 의견을 나타내고 있다.

\section{3. 학제에 대한 개선점}

4학년제로 통합에 있어 전제조건에 대한 의견으로 교수들은 임상병리 인증평가원 설립 $39.2 \%$, 교육과정의 표준화 $22.8 \%$, 법령개정 $20.3 \%$, 개설대학의 정원조정 $17.7 \%$ 순으로 조사되었 고, 병원실무자들은 개설대학의 정원조정 $33 \%$, 교육과정의 표 준화 $28.9 \%$, 임상병리 인증평가원 설립 $19.2 \%$, 법령개정 $15.7 \%$ 순으로 나타났다. 교수들은 임상병리 인증평가원 설립 이 중요하다고 인식하고 있고, 반면 병원실무자들은 개설대학 의 정원조정이 전제되어야 한다는 인식의 차이를 보여주고 있 다(Figure 3A).

4년제 통합방식에 대한 의견으로 교수들과 병원실무자들은 인증평가를 통과한 대학만이 4년제를 운영해야 한다는 의견이 각각 $49.4 \%, 57.8 \%$ 로 가장 높게 조사되었다(Figure 3B). 4년제

Table 2. The analysis of propriety of the present interdisciplinary for fostering medical technologists by Likert scale

\begin{tabular}{|c|c|c|c|c|c|c|c|c|c|c|c|c|c|c|}
\hline \multirow{3}{*}{\multicolumn{2}{|c|}{ Classification }} & \multicolumn{6}{|c|}{ Professors $(\mathrm{N}=79)$} & \multicolumn{6}{|c|}{ Medical technologists $(\mathrm{N}=1,368)$} & \multirow{3}{*}{$P$-value } \\
\hline & & \multicolumn{5}{|c|}{ Percentage (\%) } & \multirow{2}{*}{$\begin{array}{c}\text { Mean } \\
\text { (SD) }\end{array}$} & \multicolumn{5}{|c|}{ Percentage (\%) } & \multirow{2}{*}{$\begin{array}{c}\text { Mean } \\
(\mathrm{SD})\end{array}$} & \\
\hline & & 5 & 4 & 3 & 2 & 1 & & 5 & 4 & 3 & 2 & 1 & & \\
\hline \multirow{3}{*}{$\begin{array}{l}\text { Propriety of } \\
\text { fostering } \\
\text { medical } \\
\text { technologi- } \\
\text { sts }\end{array}$} & 3-year degree & 3.90 & 8.90 & 22.90 & 49.00 & 15.30 & $2.36(0.97)$ & 3.90 & 20.80 & 32.20 & 31.00 & 12.10 & $2.73(1.04)$ & 0.001 \\
\hline & $3+1$ year degree & 2.50 & 6.30 & 26.60 & 40.50 & 24.10 & $2.22(0.96)$ & 2.00 & 15.40 & 39.30 & 30.30 & 13.00 & $2.62(0.95)$ & $<0.001$ \\
\hline & 4-year degree & 34.20 & 50.60 & 7.60 & 3.80 & 3.80 & $4.08(0.95)$ & 14.30 & 42.80 & 32.00 & 8.30 & 2.60 & $3.57(0.92)$ & $<0.001$ \\
\hline
\end{tabular}

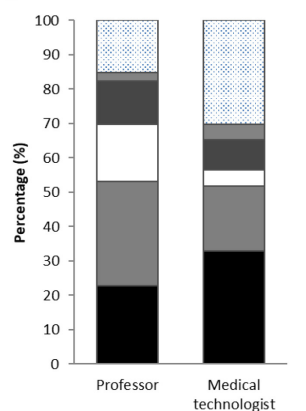

B
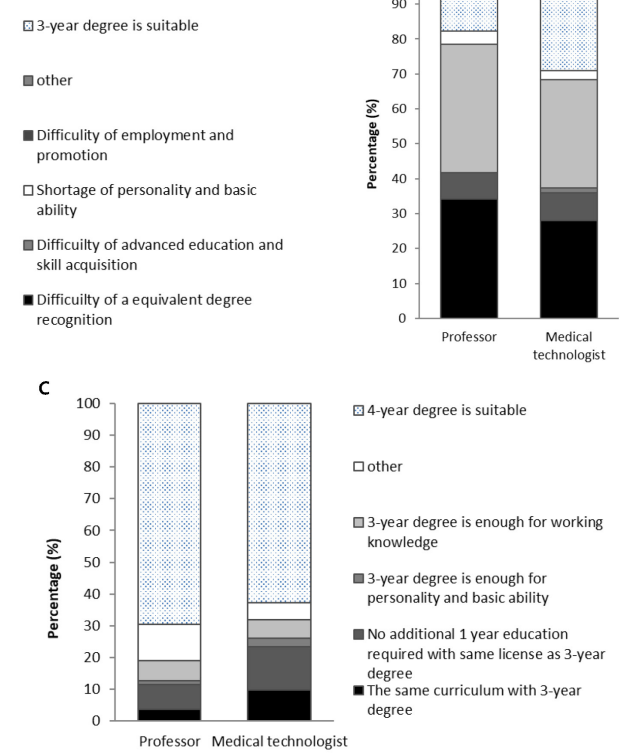

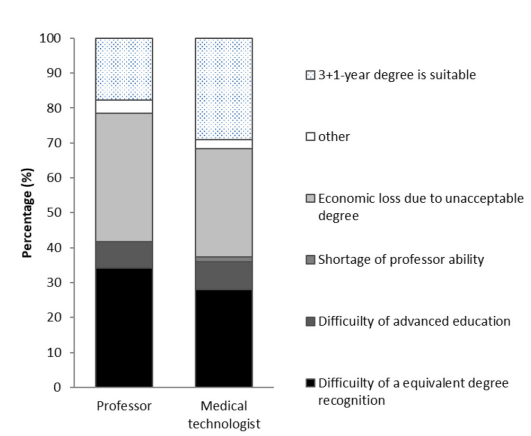

Figure 2. Analysis of the impropriety of the present interdisciplinary for fostering medical technologist between professors and medical technologists. (A) The reasons that three-year course is improper. (B) The reason that three plus one course is improper. (C) The reason that Four-year course is improper. 

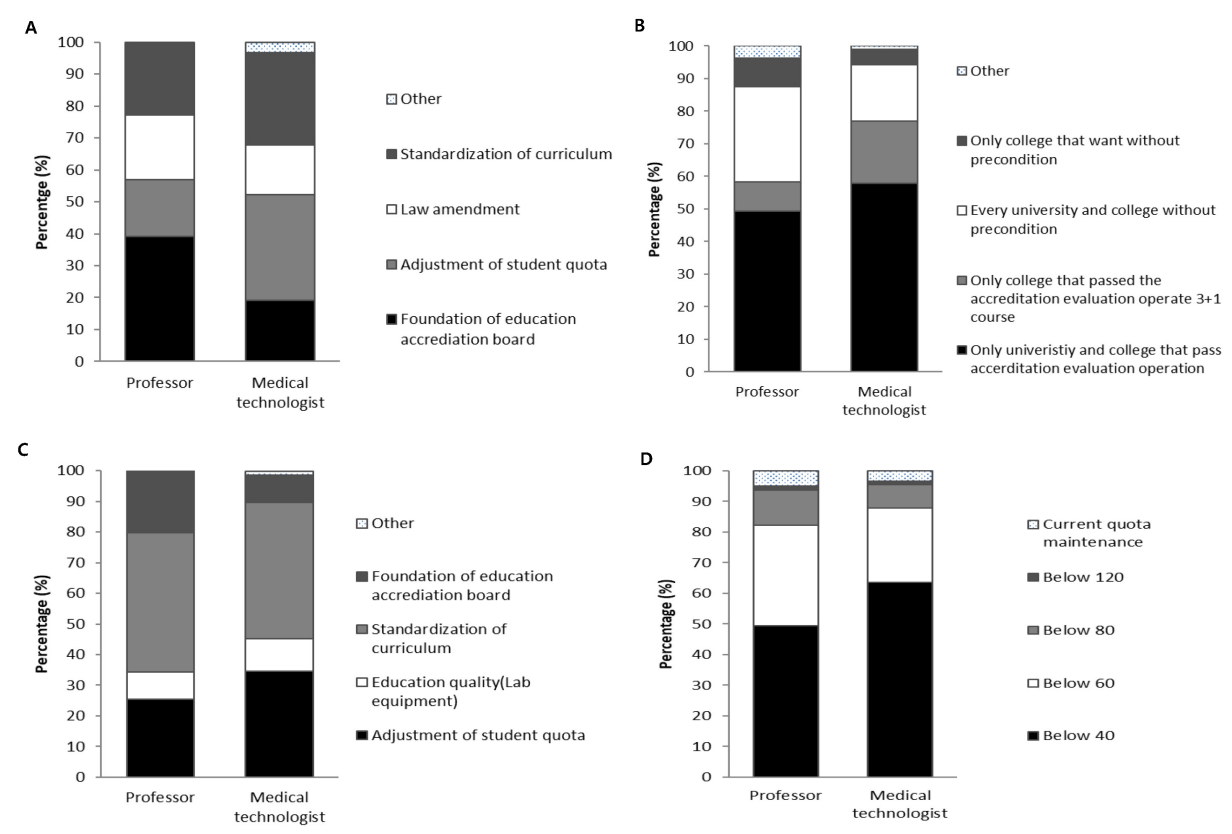

Figure 3. Analysis of the survey response for the interdisciplinary unification of 4-year course. (A) precondition for the interdisciplinary unification of 4-year course. (B) method of unification for the interdisciplinary unification of 4-year course. (C) prerequisite for the interdisciplinary unification of 4-year course. (D) student quota for the interdisciplinary unification of 4-year course.

통합의 필요조건에 대한 의견으로 교수들과 병원실무자들은 교 육과정의 표준화 각각 $45.6 \%, 44.7 \%$ 로 조사되었고, 학생정원 조정 각각 $25.3 \%, 34.6 \%$ 로 조사되었다(Figure 3C). 4년제 통합 시 대학정원의 적정인원에 대한 의견으로 교수들과 병원실무자 모두 40 명 미만이 각각 $49.4 \%, 63.7 \%$ 로 조사되었고, 60 명 미만 이 각각 $32.9 \%, 24.2 \%$ 로 조사되었다(Figure 3D).

\section{고 찰}

설문 대상자의 일반사항으로 교수들은 남자 40 60대가 대 부분을 차지했고, 병원실무자 경우 여자 20 40대가 주를 이루 고 있음을 확인하였다. 교수 학력항목에서 전문학사가 $3.8 \%$ 로 조사되었는데 이는 설문답변 오류로 판단된다. 병원실무자의 경우 전문학사 및 전문학사 졸업 후 학사 취득자의 비율이 $66.8 \%$ 의 응답을 보여주어 학제 단일화에 대한 3 년제 출신 병원 실무자들의 의견을 분석하는 좋은 표본 집단이라고 생각된다. 또한 전문대학 졸업 후 학사취득자와 일반학사취득자의 비율이 거의 동일하게 분포되었는데 이는 4년제 대학의 증가와 학제 다 양화 등이 임상현장에서 근무하는 임상병리사들의 학업의식이 많이 고취되어 있음의 결과로 생각된다. 면허취득년도의 경우 병원실무자들은 10 년 이하의 비율과 11 년 이상의 비율이 비슷 하게 조사되어 현재 젊은 임상병리사들의 학제단일화에 대한 의견을 확인할 수 있는 자료라고 사료된다. 지역별로 보면 병원 실무자들은 대부분 서울, 경기 및 광역시에 응답자의 $67.4 \%$ 가 분포되어 있음을 보여주어 이번 설문조사 대상에서는 대도시
위주의 일자리가 많이 분포하고 있음을 간접적으로 확인할 수 있었다(Table 1).

임상병리사 양성을 위한 현행 이원화되어 있는 학제에 대해 서는 교수들과 병원실무자들 모두 $75 \%$ 이상이 4년제로의 통합 이 필요하다고 조사되었고(Figure 1), 앞으로의 임상병리사 양 성에 적합한 학제를 묻는 경우에는 3 년제나 $3+1$ 과정은 적합하 지 않다는 의견이 교수와 병원실무자 모두 유의하게 높게 나타 났지만 교수집단이 좀 더 부정적인 응답을 보여주었다. 4년제 학제는 적합하다는 의견이 교수와 병원실무자 모두 유의하게 높게 나타났지만, 병원실무자와 비교하여 교수집단이 압도적 으로 적합하다는 의견의 높게 나타났다(Table 2). 우리나라는 일본과 마찬가지로 임상병리사가 진단검사의학과 업무분야 뿐 만 아니라 조직병리와 임상생리 분야까지 통합하여 교육과정이 운영되고 있고 모든 분야에서 전문성을 갖춘 인력양성을 요구 받고 있는 실정이다. 최근 일본에서도 임상병리 분야의 빠른 발 전에 대처하기 위하여 4년제 학사학위 과정의 프로그램이 확대 되고 있듯이[10], 우리나라도 의료분야의 발전이 세계 어떤 나 라 와도 비교할 수 없을 정도로 빠른 변화를 보이며 발전해 나가 고 있는 현실을 감안한다면, 4 년제 학제 통합을 통해 좀 더 전문 적인 임상병리사를 배출하는 것이 학제가 이원화되어 있고 직 무가 세분화되어 있는 미국, 캐나다, 호주와는 다른 우리나라 현 실에 적합한 학제가 될 수 있을 것이라고 생각된다[2, 11, 12]. 또한, 의료기관에 치중되어진 임상병리사의 인력보다 이외의 연구개발과 진화된 분자진단의 분양에서 역할을 펼쳐야 할 것 으로 여겨진다. 이는 의료환경의 변화와 직무능력의 다양화로 
인한 임상병리사의 역할 확대가 요구된다.

Table 2에서 조사되었던 각 학제가 적합하지 않은 구체적인 이유에 대한 조사에서 3 년제의 경우에는 동등한 학위인정의 어 려움, 심화교육과 기술습득의 어려움이 높은 응답을 보였다. 교 수들은 심화교육과 기술습득의 어려움을 가장 큰 이유라고 답 했으나, 병원실무자들은 취업현장에서 동등한 학위인정이 어 려운 점을 첫번째로 답하였다(Figure 2A). 3+1과정의 경우에 는 교수와 병원실무자들 모두 단순 학위취득 수단으로 경제적 손실만 가중한다는 점, 4 년제와 동등한 대우를 받기 어려운 점 을 이유라고 답하였다(Figure 2B). 이러한 결과들은 동일한 면 허취득과 동일한 업무를 함에도 불구하고 차별된 대우를 줄 수 밖에 없게 되는 임상병리학 학제 이원화에 따른 근본적인 문제 점을 제시해 주고 있다고 생각된다. 현재 운영되고 있는 임상병 리사 전공심화과정은 학사관리 및 교육환경 미흡, 수여된 학위 의 대내외 공신력 미흡 등으로 전공심화과정을 하나의 부수적 인 프로그램으로 여기고 있어 대학 수준의 정규교육을 희망하 는 3년제 졸업자들의 욕구를 충족시키는 데에 한계가 있다[13]. 또한 학점은행제는 부실한 학사관리와 학위 취득 검증시스템의 부재로 손쉽게 학위를 취득할 수 있어 학위 질 저하의 문제점이 대두되고 있다[14].

4년제 통합의 선제조건으로는 교수들은 임상병리인증평가 원 설립을 가장 우선순위로 답변하였고 다음으로 교육과정의 표준화로 답하였다. 반면 병원실무자들은 개설대학의 정원조 정을 가장 우선순위로 답하였고 다음순위로 교육과정의 표준화 로 답하였다(Figure $3 \mathrm{~A}$ ). 이러한 결과는 교수들은 임상병리사 양성의 질적인 향상을 위해 4년제 통합을 바라보고 있는 반면, 병원실무자들은 우선 배출인력의 감소가 전제되어야 한다는 의 견을 보인 것으로 파악된다. 4년제 통합방식은 교수와 병원실무 자 모두 인증평가를 통과한 대학만이 4년제를 운영하도록 하는 답변이 가장 높게 나타났다. 앞선 연구에서도 제시되었던 임상 병리 인증평가원 설립을 통한 객관적인 임상병리학 교육기관 인증을 요구하고 있다고 보인다(Figure 3B). 4년제 통합을 위한 필요조건으로는 교수와 병원실무자 모두 교육과정의 표준화, 학생정원조정을 답변하여 교수와 병원실무자 모두 현재 병원 취업의 어려움과 단순한 학교차이에 의한 격차를 줄이기 위한 표준화된 체계가 필요하다는 의견을 제시한 것이라 판단된다 (Figure 3 C). 이러한 결과는 기존 의학평가원과 간호교육인증 평가원 같은 인증평가기관이 효율적인 교육체계와 내용을 관리 할 수 있고 교육과정의 만족도를 제고할 수 있다는 내용과도 일 치한다 $[15,16]$. 4년제 단일화시 대학정원 적정인원은 교수와 병원실무자 모두 40 명 미만으로 해야 한다는 의견이 가장 높게
나타났다. 병원실무자들이 교수보다 40 명 미만에 대한 의견이 높은 것으로 나타나 병원에 근무하는 임상병리사들은 배출인원 너무 많다는 의견이 지배적임을 확인할 수 있었다(Figure 3D). 이전 연구에서는 교수들은 4년제 통합으로 내실 있고 충실한 교 육이 선행되고 입학정원이 적절한 조절을 통해 우수한 임상병 리사들이 배출되면 미래에 대한 긍정적인 모습을 보이고 있지 만, 병원실무자들은 현재 포화상태에 있는 병원현장에 대한 회 의적인 의견을 보임으로서 임상병리학과를 졸업하고 다양한 분 야로의 진출에 대한 의견으로 4년제 통합을 제시하였다[17]. 본 연구는 현재 대학교수와 병원실무자들이 학제 단일화에 대해 생각하고 있는 다양한 의견을 조사분석한 연구이지만, 모든 대 학교수와 병원실무자들이 참여한 조사는 아니기 때문에 조사결 과에 대한 일반화를 하기는 어려워 보이며 앞으로 더 방대한 연 구를 통한 접근이 필요해 보인다.

결과적으로, 본 연구에서 보듯이 의료환경의 다변화에 따라 시대적 요구에 부응하는 전문성을 겸비한 인재양성과 임상병리 교육과정의 표준화와 현장직무교육개선 등을 위하여 학제단일 화가 절실히 요구되고 있다. 대한임상병리사협회와 한국임상 병리학과 교수회 및 임상병리학과 재학생 등은 임상병리 교육 인증평가원의 설립을 통해 교육과정의 표준화와 상향학제단일 화를 위한 법령개정, 정원조정 등의 노력을 추진해야 할 것으로 사료된다.

\section{요 약}

임상병리학과 학제 단일화에 대한 의견을 교수와 병원근무 자들을 대상으로 설문조사 형식으로 조사하여 분석하였다. 2018년 1월 18일부터 25일까지 웹 버전의 설문지가 255명의 대학교수들과 4,000명의 병원근무자들에게 배포되었다. 회수 율은 교수들은 79명(30.9\%), 병원실무자들은 1,368명(34.2\%) 이 응답하였다. 임상병리학의 학제 이원화에 대한 인식조사에 서는 교수와 병원근무자 모두 4년제로 학제 통합이 필요하다고 조사되었다. 4년제 통합 전제조건은 임상병리 인증평가원 설립 과 교육과정의 표준화가 높게 조사되었고, 4 년제 통합의 필요조 건은 학생정원조정과 교육과정의 표준화가 높게 조사되었다. 4 년제 통합방식은 인증평가를 통과한 대학만이 4년제를 운영해 야 한다는 의견이 교수와 병원근무자 모두 가장 높게 조사되었 다. 4 년제 통합시 대학정원 적정인원은 40 명 미만이 가장 높게 조사되었다.

결론적으로 교수들과 병원실무자들은 의료환경의 급격한 변 화에 부응하는 전문성을 가진 임상병리사를 배출하기 위해서는 
임상병리학과 학제의 4년제 통합이 필수적이고, 이를 위해 임상 병리인증평가원 설립, 교육과정의 표준화, 학생정원조정 이 전 제되어야 한다고 생각하고 있음을 보여준다.

Acknowledgements: This work was supported by the Korean Association Medical Technologist research fund (2017).

\section{Conflict of interest: None}

\section{REFERENCES}

1. Cho KJ, Lee CK, Lee SG, Chung SW, Kim TU, Moon HJ, et al. A study on certifying systems for clinical laboratory scientists. J Educ Eval Health Prof. 2004;1:51-66. https://doi.org/10.3352/ jeehp.2004.1.1.51.

2. JeKal SJ, Yang MG, Lee SH, Kim DJ, Joo SI, Park JO, et al. The study of policy proposal for fostering competent Medical Technologist [Internet]. Seoul: Korean Health Personnel Licensing Examination Institute; 2017 [cited 2018 June 16]. Available from: https://rnd.kuksiwon.or.kr/last/selectLastDetail. do?MENU_ID=C-01-01\&reportno=2017082801\&sYear $=2017 \&$ sJssfc_code $=08 \&$ Researchindexcd $=$ \&researcherid $=\&$ sRsrchtasknm $=$ \&PAGE_NUM=1\&PER_PAGE=10\&IS_PAGE_NEW_SEARCH=Y\& TOTAL_PAGE $=1$.

3. Kim CH, JeKal SJ, Choi CW, Yook GD, Joo SI, Kim YS, et al. The study of long-term improvement plan of practical examination of Medical technologist [Internet]. Seoul: Korea Health Personnel Licensing Examination Institute; 2016 [cited 2018 June 16]. Available from: https://rnd.kuksiwon.or.kr/last/ selectLastDetail.do?MENU_ID=C-01-01\&reportno=20160810 01\&sYear $=2016 \&$ sJssfc_code $=08 \&$ sResearchindexcd $=\&$ re searcherid=\&sRsrchtasknm $=\&$ PAGE_NUM=1\&PER_PAGE= 10\&IS_PAGE_NEW_SEARCH=Y\&TOTAL_PAGE $=1$.

4. Choi SG, Song WH, Ahn YH, Ryu KH, Lee JH, Chang KS, et al. The study of the second Job analysis of Medical Technologist [Internet]. Seoul: Korea Health Personnel Licensing Examination Institute; 2012 [cited 2018 June 16]. Available from: https:// rnd.kuksiwon.or.kr/last/selectLastDetail.do?MENU_ID=C-01-0 $1 \&$ reportno=RE02-1206-10\&sYear $=2012 \&$ sJssfc_code $=08 \&$ sResearchindexcd=\&researcherid $=\&$ sRsrchtasknm $=\&$ PAGE NUM=1\&PER_PAGE=10\&IS_PAGE_NEW_SEARCH=Y\&TOTAL_ PAGE $=1$.

5. Kim SY, Lee JY, Joung SE. The current status of the $3+1$ curriculum implementation of nursing college in transition from a three-year to a four-year nursing education system. J Korean Acad Soc Nurs Edu. 2014;20:288-299. https://doi.org/ 10.5977/jkasne.2014.20.2.288.

6. Ahn YH, Park KS, Yang SO, Shin KR, Kim MJ. Development of standards and criteria for accreditation of baccalaureate nursing education program. J Educ Eval Health Prof. 2005; 2:87-103. https://doi.org/10.3352/jeehp.2005.2.1.87.
7. Kim KS, Lee TS, Oh TY, Kim SY, Lee HS, Oh JS, et al. The study of policy proposal for fostering competent Physical Therapist [Internet]. Seoul: Korean Health Personnel Licensing Examination Institute; 2017 [cited 2018 June 16]. Available from: https://rnd.kuksiwon.or.kr/last/selectLastDetail.do? MENU_ID=C-0101\&zreportno $=2018011508 \&$ sYear $=2017 \&$ sJssfc_code $=11 \&$ sResearchindexcd=\&researcherid= \&sRsrcht asknm $=\&$ PAGE_NUM= 1\&PER_PAGE=10\&IS_PAGE_NEW_SEARCH=Y\&TOTAL_PAGE $=1$.

8. Lee SJ. The promotion policy of 21st century human resources in science and engineering [Internet]. Seoul: PRISM; 2009 [cited 2018 June 16]. Available from: http://www.prism. go.kr/homepage/entire/retrieveEntireDetail.do;jsessionid= 68C146F6B4B815FB4069AA5F5FA63AA4.node02?cond_research_name $=\&$ cond_research_start_date $=\&$ cond_research_end_date $=\&$ research_id $=1341000-200900108 \& p a-$ geIndex=1835\&leftMenuLevel=160.

9. Hewett R. The future of medical laboratory science- a personal perspective of Dr Who. NZ J Med Lab Science. 2008;62:56-59.

10. Hosoqaya $S$. Role of medical technologists' training in the future. Rinsho Byori. 2015;63:137-140.

11. Garcia E, Fisher PB. The American Society for Clinical Pathology's 2015 wage survey of medical laboratory in the United States. Lab Med. 2017;147:113-136. https://doi.org/ 10.1093/labmed/lmx031.

12. Scanlan PM. A review of bachelor's degree medical laboratory scientist education and entry level practice in the United States. EJIFCC. 2013;24:5-13.

13. Nam KH, Hong JS, Kang MS, Shim BS, Kim MG, Park HS, et al. A study on the development of the bachelor's degree advanced course in preparation for the fourth industrial revolution [Internet]. Seoul: Korean council for university college education; 2017 [cited 2018 June 16]. Available from: http://www. kcce.or.kr/web/board/2963.do? mode=view\&schCon= \&schStr=\&schBcode=\&pageIndex=1\&pageUnit=20\&idx=50510.

14. Kim HS. The study on improvement of quality of NCS-related credit bank system [Internet]. Seoul: PRISM; 2009 [cited 2018 June 16]. Available from: http://www.prism.go.kr/homepage/ origin/retrieveOriginDetail.do?pageIndex=8\&research_id= 1342000-201400064\&cond_organ_id=1342000\&leftMenuLevel= z120\&cond_research_name $=\&$ cond_research_start_date $=$ \&cond_research_end_date=\&pageUnit=10\&cond_order=3.

15. Korean Institution of Medical education and evaluation. Selfassessment of study guidelines for 2012 accreditation of medical education and evaluation; [Internet]. Seoul: Korean Institute of Medical Education and Evaluation; 2012 [cited 2018 June 16]. Available from: http://www.kimee.or.kr/board/data/? mod=document\&uid=701.

16. Kim JH, Park JY, Yang BS. A study on the curricular satisfactions and curriculum improvements of the students majoring in clinical pathology. Korean J Clin Lab Sci. 2012;44:239-244.

17. Kim HS, Kwon PS, Kang JH, Yang MG, Park JO, Kim DJ, et al. Survey on the education system and national licensing examination for fostering competent medical technologists. Korean J Clin Lab Sci. 2017;49:161-170. https://doi.org/10.15324/kjcls. 2017.49.2.161. 